Peshawar Journal of Psychology and Behavioral Sciences, 2016, Vol. 2, No. 1, 17-29

\title{
Delinquency an Outcome of Parenting
}

\section{Madiha Asghar $^{1} \&$ Hina Iqbal $^{2}$}

\author{
Islamia College Peshawar
}

The aim of the study was to investigate and compare the role of parental discipline and parental relationship in detained delinquents and non-delinquents. Current study assessed parental factor associated with delinquency. Total sample comprised of two hundred ( $\mathrm{N}=200)$ delinquents and nondelinquents with the age range of $10-18$ year $(\mathrm{M}=15.76, \mathrm{SD}=$ 1.93). Sample of one hundred $(\mathrm{n}=100)$ male juvenile delinquents was selected from different jails of Khyber Pakhtunkhawa. And One hundred $(\mathrm{n}=100)$ male non juvenile delinquents were selected from different schools of Khyber Pakhtunkhwa through convenient sampling. It was hypothesized that that delinquent will score lower on parental relation and parental discipline. ttest, multiple regression and Logistic regression was used to explore the independent factor influencing delinquency. There were significant difference between delinquents and nondelinquents on the quality of parental relationship and parental discipline. It was revealed from the findings of the study that parenting factors contribute in delinquency. It has been found that most of juvenile commit criminal activity due to broken family such as parental separation, parental marital conflicts, and hostile behavior towards each other. Another noteworthy finding was harsh parent and strict parental discipline was found to be a pertinent contributor of delinquency. It was concluded that parental discipline and parental marital relationship significantly contribute towards delinquency in children and adolescents.

\footnotetext{
${ }^{1}$ Assistant Professor, Department of Psychology, Islamia College Peshawar

${ }^{2}$ Lecturer, Department of Psychology, Islamia College Peshawar
} 
Keywords. Juvenile delinquency, parenting, parental hostile behavior, parental separation, parental marital conflicts

Juvenile delinquency is a serious social problem (Cater \& Stewan, 1999; Haper \& Ibrahim, 1999) and threat to the peace of the society. Agnew (1992) defined the concept of juvenile delinquency as prohibited acts including material goods offenses and violent offenses committed by teenager at the age of 18 or below. Schwartz and Johnson (1985) concluded the word juvenile is used for those children who are under the age of 18 years and commit criminal acts for which there is age not suitable. Another definition of juvenile delinquency by Regoli and Hewitt (2002) is Juvenile delinquency is defined as a child's malevolent action increases in the occurrence in following three categories frequency, seriousness and duration.

Delinquents show more behavioral problem due to their disturbed social and family environment. There are many risk factors, which contribute in determining delinquency. Chambers, Power, Loucks, and Swanson (2001) found that high parental control, such as authoritarian parenting style, leads to a faster first arrest. They also discovered that low parenting care, such as in a permissive parenting style, is related to high levels of distress in adolescents. These finding would also indicate harmful results from being reared in a permissive or authoritarian home.

A study, which was conducted, by Kim and Kim (2008) examined that those children who are labelized as delinquents reported higher level of parental dissatisfaction and they have more parental marital disharmony. They also indicated such kinds of children who are the victim of domestic, physical violence and familial problems are more vulnerable to delinquency.. Poor parental guidance is a negative family traits which enhance the ratio of delinquency in children and these factors are considered to be risk factors, while the families which give support and warmth to child it develop resilience which is called protective factor and it prevent child even in adverse condition (Derzon, 2005).

If there is any arrest in the family such as father, mother, sibling or any other blood relation may predict delinquency in children, importantly father arrest has greater impact on child delinquency 
s(Farrington et al., 2001). After Poor parental supervision convicted older siblings is another important cause to develop delinquency ( Farrington, Coid, \& Murray, 2009). In another study conducted by Smith and Farrington (2004) which revealed that demanding parenting and parental conflict are intervening factor for developing antisocial behavior and conduct disorder. A study conducted by Sampson and Laub (1993) revealed that parental deviance do not predict delinquency if the risk factors such as poor parental control and supervision. Little attachment, huge family size is controlled. Jaffee et al. (2001) found that there is link between teenager mother and delinquency in by providing harsh parental discipline, and disturbed family pattern.

Lamborn et al., (1991) conducted study on parenting style and found authoritarian parents do not develop personality confidence and social capability to deal with social stressors so these deficit may develop delinquency in children, and if they would have been raised in permissive homes they have lowest level social independence. Loeber and Stouthamer-Loeber (1986) examined that characteristics of parenting style usually associated with anti social personality and development of problematic behavior. Unavailability of parental emotional support, no supervision provided to the children and bearing rejection from parental side are important factor for developing delinquency in adolescents. Another study found that indifferent parenting and environment in the home undesirably affect child's development thus lead to delinquency (Mamari, Blum, \& Tuefel-Shone, 2010). Parental relationship is another important aspect for causing delinquency this aspect had revealed by Dekovic (1999) found that the negative quality of relationships between the adolescents and their parents is related to higher levels of externalizing problems, Nelson, Rutherford, \& Wolford (1996) concluded that these externalizing problems are disturbing others, verbal and physical aggression, and acts of violence . Another study, which was conducted by Kim and Kim (2008) examined that those children who are labeled as delinquents reported higher level of parental dissatisfaction and they have more parental marital disharmony. They also indicated such kinds of children who are the victim of domestic, physical violence and familial problems are more vulnerable to delinquency.

\section{Objectives}


- To examine the effect of parental relationship in Delinquents and non delinquents.

- To compare the role of parental discipline in delinquents and non delinquents.

- To ascertain the association between parental relationship, parental discipline and delinquency among delinquents and non delinquents.

\section{Hypotheses}

- There will be a significant relationship between parental marital disharmony and delinquency.

- There will be a significant relationship between parental discipline and delinquency.

- Delinquents will score high on perceived parental marital conflict than non delinquents.

- Delinquents will score high on parental discipline than non delinquents.

\section{Method}

\section{Sample}

The sample was consist of the total two hundred $(\mathrm{N}=200)$ delinquents and non-delinquents with age range of $10-18$ years $(\mathrm{M}=15.7$ $\mathrm{SD}=1.94)$. It consisted of one hundred $(\mathrm{n}=100)$ detained juvenile delinquents and one hundred $(n=100)$ non delinquents from Khyber Pakhtunkhwa. Detained delinquents were comprised of all the delinquents in different prisons of Khyber Pakhtunkhwa. Non delinquents were selected from the schools of Haripur and Peshawar (Khyber Pakhtunkhwa). Convenient sampling technique was used for selection of sample.

\section{Instruments}

The following tools have been used 


\section{Parental Relation Scale}

Self constructed questionnaire of Parental relation scale has been used. The scale consisted of 20 items with five points likert scale. The maximum score on this instrument was 100 and minimum score was 20 .

\section{Parental Discipline Scale}

Self constructs questionnaire has been used. The Parental discipline scale consisted of 6 items, with five point likert scale. The maximum scores on this scale would be 35 and minimum score would be 5. The reliability of the instrument is $\mathrm{p} .810$.

\section{Self-Reported Delinquency Scale}

This scale was developed and by Naqvi (2007). The basic purpose is to measure the juvenile tendencies. It comprises of twentyseven items. It is a self reported measure constructed in Urdu so that Pakistani citizens can understand and answer the questions. The lowest score on the scale is 27 whereas highest score is 135 . High scores on the scale show high delinquent tendencies while low score indicates less delinquent tendencies among young adulthood. The reliability of the test is .76.

\section{Procedure}

The study formally started with the formal permission from jail department and school of Khyber Pakhtunkhawa. Data was individually collected from the jails with the help of psychologist working in jail due to current law and order situation in Khyber Pakhtunkhawa. Questionnaires were filled in group in school children in their schools. Before formal data collection a consent letter was signed by every 
subject and was briefed about the study. Rapport was established and all the non delinquents were given questionnaire in the same sequence and were requested for their honest replies. However delinquents were individually interviewed in a same sequence by a trained psychologist working in the jail.

\section{Results}

Table 1

Summary of Inter correlations $(\mathrm{N}=200)$

\begin{tabular}{|c|c|c|c|c|c|c|}
\hline & Measure & 1 & 2 & 3 & $\mathrm{M}$ & SD \\
\hline 1 & P.dis & - & $.315^{* *}$ & $-.235^{*}$ & 21.10 & 4.12 \\
\hline 2 & Del.T & $.423 * *$ & - & -.070 & 34.95 & 14.54 \\
\hline 3 & PR & $.230 *$ & $.230 *$ & - & 54.14 & 8.717 \\
\hline M & & 11.45 & 3.94 & 51.25 & & \\
\hline SD & & 3.988 & 5.029 & 6.389 & & \\
\hline
\end{tabular}

Note. Inter correlation for Delinquents $(n=100)$ are Presented Above the Diagonal, and Inter Correlations for Non Delinquent $(n=100)$ are Presented Below the Diagonal. Means and Standard Deviations for Delinquents $(N=100)$ are Presented in the Vertical Columns and Mean and Standard Deviations for Non Delinquents are Presented in Horizontal Rows. For all Scales, Higher Scores are Indicative of More Extreme Responding in the Direction Of Construct Assessed. Con.t $=$ Conduct Scale; P.dis = Parental Discipline Scale; Del.T =Delinquency Scale; NPI.Tot =Neuropsychological Impairment Scale; FR =Family Relation Scale; $P R=$ Parental Relation Scale; SRMEI= Self Reported Measure of Emotional Intelligence. SE.Tot $=$ Self Esteem Scale; Pro.S $=$ Pro Social Scale.

Table 2 
Parental Relation as Predictors of Delinquency among Delinquents and Non delinquents $(\mathrm{N}=200)$

\begin{tabular}{lllllll}
\hline & Delinquents $(\mathrm{n}=100)$ & \multicolumn{3}{c}{ Non-delinquents $(\mathrm{n}=100)$} \\
& \multicolumn{1}{c}{$\mathrm{B}$} & $\mathrm{SE}(\mathrm{B})$ & $\mathrm{B}$ & $\mathrm{B}$ & $\mathrm{SE}(\mathrm{B})$ & $\mathrm{B}$ \\
\hline Constant & 1.536 & 9.846 & & -5.33 & 3.99 & \\
& $(-17.89,20.96)$ & & & $(-13.26,2.59)$ & & \\
PR & .325 & .186 & .128 & .181 & $.077^{*}$ & .230 \\
& $(-.041, .691)$ & & & $(.027, .335)$ & & \\
\hline
\end{tabular}

Note. Delinquents $R^{2}=.016$. Non-Delinquents $R^{2}=.013 .{ }^{*} p<. .05$,

$*^{*} p<.01, *^{* *} p<.001$. PR: Parental Relation Scale

Table 2 shows Linear regression analysis predicting delinquency based to on parental relation. A non significant regression equation was found $\mathrm{F}(1,85), 3.07, \mathrm{p}<.876$. The model explained $16 \%$ of variance with $\mathrm{R}^{2}$ of .016. Parental relation is not a strong predictor of delinquency.

Table 3

Parental Discipline as Predictors of Delinquency $(\mathrm{N}=200)$

\begin{tabular}{|c|c|c|c|c|c|c|}
\hline & \multicolumn{3}{|c|}{ Delinquents $(\mathrm{n}=100)$} & \multicolumn{3}{|c|}{ Non-delinquents $(\mathrm{n}=100)$} \\
\hline & $\mathrm{B}$ & $\mathrm{SE}(\mathrm{B})$ & $\mathrm{B}$ & $\mathrm{B}$ & $\mathrm{SE}(\mathrm{B})$ & $\mathrm{B}$ \\
\hline Constant & $\begin{array}{l}-17.80 \\
(-22.65,- \\
12.95)\end{array}$ & $\begin{array}{l}2.45^{*} \\
* *\end{array}$ & & $\begin{array}{l}-2.17 \\
(-4.94, \\
.602)\end{array}$ & 1.39 & \\
\hline p.dis & $\begin{array}{l}2.27 \\
(1.99 \\
2.55)\end{array}$ & $\begin{array}{l}.143^{*} \\
* *\end{array}$ & .761 & $\begin{array}{l}.534 \\
(.305 \\
.763)\end{array}$ & $.115^{*}$ & $\begin{array}{l}.42 \\
3\end{array}$ \\
\hline
\end{tabular}

Note. Delinquents $R^{2}=.579$. Non-Delinquents $R^{2}=.179 .{ }^{*} p<. .05$,

$*^{* *} p<.01, * * * p<.001 . p$.dis: Parental Discipline Scale

Linear regression analysis is used to predict delinquency based on Parental discipline. A significant regression equation was found $\mathrm{F}$ (1, $85), 254.22, \mathrm{p}<.001$. The model explained $57 \%$ of variance with $\mathrm{R}^{2}$ of .579. Parental discipline is a strong predictor of delinquency. 
Table 4

Mean Difference Standard Deviation, t-Value of Delinquents and Non Delinquents on Parental Relation Scale $(\mathrm{N}=200)$

\begin{tabular}{|c|c|c|c|c|c|c|c|c|}
\hline \multicolumn{2}{|c|}{$\begin{array}{l}\text { Delinquents } \\
(\mathrm{n}=100)\end{array}$} & \multicolumn{2}{|c|}{$\begin{array}{l}\text { Non Delinquent } \\
\quad(\mathrm{n}=100)\end{array}$} & \multirow{3}{*}{$\mathrm{t}(198)$} & \multirow{3}{*}{$\mathrm{p}$} & \multirow{2}{*}{\multicolumn{2}{|c|}{ CI $95 \%$}} & \multirow{3}{*}{ Cohen's d } \\
\hline \multirow[t]{2}{*}{ M } & \multirow[t]{2}{*}{ SD } & \multirow[t]{2}{*}{$\mathrm{M}$} & \multirow[t]{2}{*}{ SD } & & & & & \\
\hline & & & & & & LL & UL & \\
\hline 54.14 & 8.71 & 51.25 & 6.38 & -2.67 & $<.001$ & -5.022 & -.758 & 2.39 \\
\hline
\end{tabular}

Table 4 the difference between delinquent and non delinquents. On parental relation scale Delinquents $(\mathrm{M}=54.14, \mathrm{SD}=8.71)$ scored higher than non delinquents $(\mathrm{M}=51.25, \mathrm{SD}=6.38), \mathrm{t}(918)=-2.67$ with mean difference $-2.89, \mathrm{p}<.001, \mathrm{~d}=2.39$, CI 95\% [ -5.022, -.758] the effect size of this analysis was found to exceed Cohen's (1988) convention for large effect (.80).

Table 5

Mean Difference Standard Deviation, t-Value of Delinquents and Non Delinquents on Parental Discipline Scale $(\mathrm{N}=200)$

\begin{tabular}{|c|c|c|c|c|c|c|c|c|}
\hline \multicolumn{2}{|c|}{$\begin{array}{l}\text { Delinquents } \\
(\mathrm{n} 100=)\end{array}$} & \multicolumn{2}{|c|}{$\begin{array}{l}\text { Non Delinquent } \\
(\mathrm{n}=100)\end{array}$} & \multirow{3}{*}{$\mathrm{t}(198)$} & \multirow{3}{*}{$\mathrm{p}$} & \multirow{2}{*}{\multicolumn{2}{|c|}{ CI $95 \%$}} & \multirow{3}{*}{ Cohen's d } \\
\hline \multirow[t]{2}{*}{ M } & \multirow[t]{2}{*}{ SD } & \multirow[t]{2}{*}{$\mathrm{M}$} & \multirow[t]{2}{*}{ SD } & & & & & \\
\hline & & & & & & LL & UL & \\
\hline 12.61 & 21.10 & 4.12 & 3.98 & -16.82 & $<.001$ & -10.78 & -8.51 & 2.39 \\
\hline
\end{tabular}

Note. Higher the Score on Strict Parental Discipline Scale Higher the Level of Delinquency Among Subjects.

Table 5 the difference between delinquent and non delinquents. On parental discipline scale Delinquents $(\mathrm{M}=12.61, \mathrm{SD}=1.83)$ scored higher than non delinquents $(\mathrm{M}=12.61, \mathrm{SD}=21.10), \mathrm{t}(918)=-16.82$ with mean difference $8.49, \mathrm{p}<.001, \mathrm{~d}=3.39$, CI 95\% [ $-10.78,-8.51]$ the effect size of this analysis was found to exceed Cohen's (1988) convention for large effect (.80). 
Table 6

Logistic Regression Analysis of Psychosocial Factor Among Delinquents and Non Delinquents $(\mathrm{N}=200)$

\begin{tabular}{lllll}
\hline & & \multicolumn{2}{c}{$95 \%$ CI for Odds Ratio } \\
\cline { 3 - 5 } Variables & $\mathrm{B}(\mathrm{SE})$ & $\begin{array}{l}\text { Lower } \\
\text { Limit }\end{array}$ & $\begin{array}{l}\text { Odds } \\
\text { Ratio }\end{array}$ & $\begin{array}{c}\text { Upper } \\
\text { Limit }\end{array}$ \\
\hline Constant & $-11.409(2.077) * * *$ & & \\
P.dis & $.543(.076)^{* * *}$ & 1.383 & 1.483 & 1.996 \\
PR & $.048\left(.028^{*}\right.$ & .748 & .993 & 1.109 \\
\hline Note. $R^{2}=.563\left(\right.$ Cox \& Snell), $R^{2}=.751$ (Nagelkerke). Model Chi-Sq. \\
$(d f=8), 12.67$, \\
$p$ value $=.124 . *{ }^{*} * 0.05, * *=p<.01 \& * * *=p<.001$.
\end{tabular}

The table 6 shows logistic regression analysis predicting conduct disorder, and parental discipline as predictors of delinquency. A test of the full model against a constant only a model (conduct disorder) was statistically significant (chi square 12.67, $\mathrm{p}>.124, \mathrm{df}=8$ ). Nagelkerke's $\mathrm{R}^{2}$ indicated that there was strong relationship between predicting and grouping. The walden criterion demonstrate that parental discipline made a significant contribution to the prediction $(p<.001)$. Parental relation was slightly significant. $\operatorname{Exp}(B)$ value of parental discipline is also increased.

\section{Discussion}

Inadequate parental supervision, particularly at the age of middle and high school increases the likelihood of significant involvement in a deviant peer group (Mash \& Barkley, 1998). Monitoring becomes increasingly important as children move into adolescence and spend less time under the supervision of their parents or other adults and more time with their peers (Moffitt, 1993). Zeman and Bressan (2008) explored youth delinquency using data from the 2006 International Youth Survey in Toronto. They found that youth who reported a positive relationship with their father and/or mother were less likely to report violent delinquency. 
The effect of marital conflict on youth antisocial behavior may be affected by many factors including: demographic factors, parents' unavailability, the use of inconsistent or harsh discipline, poor monitoring, and how the child interprets conflict between parents (Cummings \& Davies, cited in Mash \& Wolfe, 2007). Home environments have been found to predict early onset and chronic patterns of delinquent or antisocial behavior in children and youth (McEvoy\& Welker, 2000). Other factors, such as parental criminality, harsh and ineffective parental discipline, lack of parental involvement, family conflict, child abuse and/or neglect, and rejection by parents have also been identified as important factors related to delinquent behavior (Patterson, Forgatch, \&Stoolmiller, 1998; Walker, Stieber, Ramsey, \& O'Neill, 1991). conflicting quality of parent-adolescent relationships leads to adolescent maladjustment (Inge, Maja, \& Anne, 2006). Adolescent deviant behavior from the social norms is also associated with parents' relationship with adolescents.

\section{Conclusion}

The present study found that juvenile delinquent has psychosocial and familial problem. Before conducting study plan different hypotheses were made to check the credibility. Hypotheses were structured around the parental discipline and parenting relationship. It was assumed that those children who transgress are just because of their parental discipline. If parent uses harsh parenting, Rejection may have given to the child or if parent uses harsh discipline, and abusive language such kind of derogative behavior leads child to delinquency. Parental relation is another very important factor. The current study focuses on the tow different aspects such as parental discipline and parental relations, parental discipline may be replace with child discipline. So child discipline or parental discipline may be defined as values, beliefs, custom and education which is provided to the child according to their age and such kind of process develops specific kind of temperament. While parental relation is the quality of time the parent spend with their kids. Current study focuses that children bear harsh parental discipline, emotional frustration are more prone to delinquent behavior. Such emotional disturbances develops negative out come in 
child for example school truancy, academic problem, disturb peer relationship. So, if there is disturbance in parenting it may be the causal factor of delinquency. On contrary non delinquents do not bear such derogative behavior harsh parenting style, negligence or any kind of emotional tension and frustration. To prevent a child from becoming delinquents focus should be correctional strategies of parenting discipline, and parental relationship.

\section{Limitation of the Study}

Limitations of the study are following;

Small sample size and convenient sampling technique limits the generalizability of the findings over a large population.

$>$ Due to law and order situation and unstable circumstance of the area could not approach all jails of Khyber Pakhtunkhwa.

\section{References}

Chambers, 1., Power, K, Loucks, N. \& Swanson, V. (2001). The Interaction of Perceived Maternal and Paternal Parenting Styles and Their Relation With the Psychological Distress and Offending Characteristics of Incarcerated Young Offenders. Journal of Adolescence, 24, 209-227.

Cunningham, W. and Correia, M. (2003), Caribbean youth development: Issues and policy directions. Washington DC: The World Bank.

Deković, M., Janssens, J. M. A. M. and Van As, N. M. C. (2003). Family predictors of antisocial behavior in adolescence. Family Process, 42, 223-235.

Derzon, J. H. (2005). Family features and problem, aggressive, criminal, or violent behavior: A meta-analytic inquiry. Unpublished manuscript. Calverton, MD: Pacific Institutes for Research and Evaluation.

Farrington, D.P., Coid,J.W., \&Murray,J.(2009). Family factors in the integrational transmission of offending. Criminal Behaviour and Mental Health, 19(2), 109-124. 
Inge, B.W., Maja, D., \& Anne, M.M. (2006). Parenting behavior, quality of the parent adolescent relationship, and adolescent functioning in four ethnic groups. The Journal of Early Adolescence, 26, 133.

Jaffee,S., Caspi,A.,Moffitt, T.E., Belsky, J.,\& Silva, P.A. (2001). Why are children born to teen mothers at risk for adverse outcomes in young adulthood? Results from a 20-year longitudinal study. Developmental and Psychopathology, 13, 377-397.

Kim, H., \& Kim, H. (2008). Juvenile delinquency and youth crime. New York: Nova Science Publishers.

Lamborn, S. D.;Mounts, N. S., Steinberg, L., \& Dornbusch, S. M. (1991). Patterns of competence and adjustment among adolescents from authoritative, authoritarian, indulgent, and neglectful families. Child Development, 62, 1049-1065.

Loeber, R., \& Stouthammer-Loeber, M. (1986). Family factors as correlates and predictors of juvenile conduct problems and delinquency. In M. Tonry and N. Morris (Eds.), Crime and justice, vol. 7. Chicago: University of Chicago Press.

Mamari, N.K., Blum, W.R., \& Teufel-Shone, N. (2010). What increase risk and protection for delinquent behaviors among American India youth? Findings from three tribal communities. Youth \& Society, $41,382-413$

McEvoy, A., \& Welker, R. (2000). Antisocial behavior, academic failure, and school climate: A critical review. Journal of Emotional \& Behavioral Disorders, 8, 130- 140.

Nelson, C. (1996). Introduction. In C. Nelson, R. Rutherford, \& B. Wolford (Eds.), Comprehensive and collaborative systems that work for troubled youth: A national agenda (pp. 5-14). Richmond, KY: National Juvenile Detention Association

Patterson, G.R., Forgatch, M., Yoerger, K., \& Stoolmiller, M. (1998).Variables that initiate and maintain an early-onset trajectory for juvenile offending. Development and Psychopathology, 10, 531-547.

Regoli, R. M. \& Hewitt, J. D. (2003). Delinquency in society (5th ed.). Boston: McGraw-Hill.

Sampson, R. J., \&Laub, J. H. (1993). Crime in the making: Pathways and turning points through life. Cambridge, MA: Harvard University Press. 
Schwartz, M., \& Johnson, J. H. (1985).Psychopathology of Childhood: A Clinical -Experimental Approach.(2nd ed). Pergam on General Psychology Series, pg 309.

Walker, H. M., Stieber, S., Ramsey, E., \& O'Neill, R. E. (1991).Longitudinal prediction of the school achievement, adjustment, and delinquency of antisocial versus atrisk boys. Remediation and Special Education, 12(4), 43-51.

Peshawar Journal of Psychology and Behavioral Sciences, 2016, Vol. 2, No. 1, 17-29 